\title{
Pembangunan Sistem Informasi Kartu menuju Sehat (KMS) Balita Berbasis $W E B$ Studi Kasus: Posyandu KASIH BUNDA II
}

\author{
Romzah $^{1}$, Yohanes Eka Wibawa ${ }^{2}$, Pramitha Dwi Larasati ${ }^{3}$ \\ ${ }^{12}$ Program Studi Teknik Informatika, Universitas Tanri Abeng, Jakarta \\ ${ }^{3}$ Program Studi Sistem Informasi, Universitas Tanri Abeng, Jakarta \\ romzah@student.tau.ac.id ${ }^{1}$,yohanes.eka@tau.ac.id ${ }^{2}$, pramitha.dwi@tau.ac.id ${ }^{3}$
}

Diterima : 23 Februari 2021

Disetujui : 28 Maret 2021

\begin{abstract}
Posyandu (Pos Layanan Terpadu) Kasih Bunda II berfungsi sebagai pelayanan kesehatan masyarakat yang berfokus untuk kesehatan balita. Posyandu ini memberikan pelayanan kesehatan seperti pengukuran berat badan, tinggi badan, pemberian vitamin $A$, pemberian obat cacing dan pemberian imunisasi dasar untuk balita. Pencatatan, pendatan serta pengarsipan pada posyandu dilakukan dengan media penulisan, sehingga membutuhkan waktu 1 (satu) hari dalam penyelesaiannya. Informasi-informasi mengenai posyandu tidak tersampaikan seperti sulitnya mendeteksi perkembangan balita karena tidak ada laporan yang mendukung (harus memilah satu persatu data balita). Salah satunya dalam pengisian Kartu Menuju Sehat (KMS) balita, pengisian dapat dibuat lebih efektif dan efisien dengan dibuat secara digital, pengisian KMS tidak perlu melewati tahap yang panjang karena pencatatan, perhitungan, pelaporan terlalu rumit dengan bukubuku laporan yang banyak. Fokus dari penelitian adalah membangung sistem informasi menggunakan metode waterfall sistem dan bahasa pemrograman PHP serta Database MySQL. Sistem informasi ini dirancang dengan menggunakan UML (Unified Modeling Language) yang terdiri dari Usecase Diagram, Activity Diagram, Sequence Diagram serta Class Diagram. Hasil dari penelitian ini adalah sistem informasi berbasis web yang dapat mengelola data posyandu dan membantu pelaksanaan posyandu serta menyimpan arsip-arsip posyandu. Mendapatkan laporan semua balita, data kunjungan balita dan laporan grafik status gizi balita untuk orang tua.
\end{abstract}

Index Terms-Sistem Informasi, Kartu Menuju Sehat, Posyandu, PHP

\section{PENDAHULUAN}

Posyandu adalah bentuk Upaya Kesehatan Bersumber daya Masyarakat (UKBM) yang dikelola dari, oleh, untuk, dan bersama masyarakat, untuk memberdayakan serta memudahkan masyarakat untuk mendapatkan pelayanan kesehatan dasar bagi ibu, bayi dan anak balita [1]. Posyandu Kasih Bunda II adalah sebuah pelayanan kesehatan yang memberikan pelayanan kesehatan seperti pengukuran berat badan, tinggi badan, pemberian vitamin $\mathrm{A}$, pemberian obat cacing dan pemberian imunisasi dasar Posyandu juga memberikan makanan sehat untuk balita. Dari berbagai pelayanan kesehatan yang diberikan sudah lengkap dan baik, sayangnya data perkembangan balita di posyandu ini masih dilakukan secara manual. Salah satunya dalam pengisian Kartu Menuju Sehat (KMS) balita.
Kartu Menuju Sehat (KMS) adalah kartu yang berisikan kurva pertumbuhan normal anak dalam indeks antropometri berat badan menurut umur [6]. Dengan KMS hambatan serta permasalahan pertumbuhan atau resiko kelebihan gizi akan diketahui lebih dini, sehingga upaya serta tindakan pencegahan dilakukan secara cepat dan tepat sebelum terjadi masalah yang lebih serius. Fungsi KMS secara umum sebagai alat untuk mengontrol pertumbuhan, sebagai catatan pelayanan kesehatan anak dan juga sebagai alat edukasi. Mengetahui status petumbuhan balitanya dan kapan sebaiknya anak mendapatkan imunisasi dan vitamin A adalah kegunaan dari KMS bagi orang tua [6]. Sedangkan bagi kader posyandu adalah sebuah media penyuluhan ibu-ibu balita dan bagi petugas kesehatan KMS adalah media yang efektif dan cepat untuk mengetahui pelayanan kesehatan yang diterima oleh si anak, 
khususnya imunisasi dan vitamin A. KMS dapat digunakan oleh petugas kesehatan untuk memberikan edukasi kepada ibu-ibu mengenai makanan yang bergizi guna meningkatkan status gizi anak. Parameter status gizi balita dalam penelitian ini dengan menggunakan indeks antropometri dari Kemenkes RI, dihitung berdasarkan usia balita dan berat balita dengan 4 keterangan status gizi yaitu status gizi lebih, gizi baik, gizi kurang dan gizi buruk. Dapat dilihat pada tabel 1 dibawah ini [1];

Tabel 1. Tabel Indeks Antropomentri

\begin{tabular}{|c|c|c|c|c|}
\hline $\begin{array}{c}\text { Umur } \\
\text { dalam } \\
\text { bulan) }\end{array}$ & $\begin{array}{c}\text { Gizi } \\
\text { Buruk } \\
(\mathrm{Kg})\end{array}$ & $\begin{array}{c}\text { Gizi } \\
\text { Kurang } \\
(\mathrm{Kg})\end{array}$ & $\begin{array}{c}\text { Gizi Baik } \\
(\mathrm{Kg})\end{array}$ & $\begin{array}{c}\text { Gizi } \\
\text { Lebih } \\
(\mathrm{Kg})\end{array}$ \\
\hline 0 & 1.9 & $2.0-2.3$ & $2.4-4.2$ & 4.3 \\
\hline 1 & 2.1 & $2.2-2.8$ & $2.9-5.5$ & 5.6 \\
\hline 2 & 2.5 & $2.6-3.4$ & $3.5-6.7$ & 6.8 \\
\hline 3 & 3.0 & $3.1-4.0$ & $4.1-7.6$ & 7.7 \\
\hline 4 & 3.6 & $3.7-4.6$ & $4.7-8.4$ & 8.5 \\
\hline 5 & 4.2 & $4.3-5.2$ & $5.3-9.1$ & 9.2 \\
\hline 6 & 4.8 & $4.9-5.8$ & $5.9-9.7$ & 9.8 \\
\hline 7 & 5.3 & $5.4-6.3$ & $6.4-10.2$ & 10.3 \\
\hline 8 & 5.8 & $5.9-6.8$ & $6.9-10.7$ & 10.8 \\
\hline 9 & 6.2 & $6.3-7.1$ & $7.2-11.2$ & 11.3 \\
\hline 10 & 6.5 & $6.6-7.5$ & $7.6-11.6$ & 11.7 \\
\hline 11 & 6.8 & $6.9-7.8$ & $7.9-11.9$ & 12.0 \\
\hline 12 & 7.0 & $7.1-8.0$ & $8.1-12.3$ & 12.4 \\
\hline 13 & 7.2 & $7.3-8.2$ & $8.3-12.6$ & 12.7 \\
\hline 14 & 7.4 & $7.5-8.4$ & $8.5-12.9$ & 13.0 \\
\hline 15 & 7.5 & $7.6-8.6$ & $8.7-13.1$ & 13.2 \\
\hline 16 & 7.6 & $7.7-8.7$ & $8.8-13.4$ & 13.5 \\
\hline 17 & 7.7 & $7.8-8.9$ & $9.0-13.6$ & 13.7 \\
\hline 18 & 7.8 & $7.9-9.0$ & $9.1-13.8$ & 13.9 \\
\hline 19 & 7.9 & $8.0-9.1$ & $9.2-14.0$ & 14.1 \\
\hline 20 & 8.0 & $8.1-9.3$ & $9.4-14.3$ & 14.4 \\
\hline 21 & 8.2 & $8.3-9.4$ & $9.5-14.5$ & 14.6 \\
\hline 22 & 8.3 & $8.4-9.6$ & $9.7-14.7$ & 14.8 \\
\hline 23 & 8.4 & $8.5-9.7$ & $9.8-14.9$ & 15.0 \\
\hline 24 & 8.9 & $9.0-10.0$ & $10.1-15.6$ & 15.6 \\
\hline & & & & \\
\hline 17 & \\
\hline & & \\
\hline
\end{tabular}

Dengan memanfaatkan teknologi yang saat ini berkembang pesat, tentunya sistem pengisian KSM dapat dibuat lebih efektif dan efisien dengan dibuat secara digital. Manfaat dan keuntungan untuk orang tua balita dapat melihat langsung perkembangan anak dengan melihat grafik sesuai status gizi dengan cepat tanpa harus mencari KMS yang berbentuk kartu dan gampang rusak. Para kader posyandu bisa mengisi data secara langsung tanpa harus melakukan proses catat-mencatat yang banyak karena seluruh data terintegrasi disimpan di database. Pengisian KMS tidak perlu melewati tahap yang panjang karena pencatatan, perhitungan, pelaporan terlalu rumit dengan buku-buku laporan yang banyak. Sehingga sulit mendeteksi perkembangan balita karena tidak ada laporan yang mendukung (harus memilah satu persatu data balita).

Berdasarkan permasalahan yang telah dijabarkan, maka penelitian ini berfokus dalam membuat suatu sistem informasi KMS sebagai otomatisasi sarana penyimpanan data, yang akan lebih mudah dikontrol dan menyajikan infromasi yang lebih teratur. Membuat laporan data balita yang terintegrasi dengan sistem dan database Posyandu Kasih Bunda II serta menampilkan laporan grafik data balita sehingga para orang tua dapat lebih mudah memantau perkembangan gizi.

\section{LANDASAN TEORI}

Penulisan ini dilakukan dengan mengkaji beberapa penelitian terkait sebagai acuan penulis.

Menurut Widiana dan Bambang, sistem yang terkomputerasisasi sangat membantu dalam menyelesaikan masalah yang dihadapi terkait pendataan data balita secara manual dan mempercepat proses pembuatan laporan pada posyandu Desa Ploso Kec. Punung Kab. Pacitan [2]. Sistem informasi posyandu kesehatan ibu dan anak ini membantu kader dan bidan melaksanakan kegiatannya di Posyandu. Kegiatan tersebut antara lain; pendataan ibu dan anak, penimbangan balita, pendataan ibu hamil serta pendataan PUS KB. Sistem pada penelitian ini mampu menampilkan form dan laporan sesuai dengan di buku SIP berdasarkan hasil dari pengujian sistemnya. Sistem dapat membantu kader untuk menentukan status gizi balita berdasarkan tabel antropometri penentuan standar gizi balita yang dikeluarkan oleh Menteri Kesehatan RI [4].

Dalam penelitian yang dikemukakan oleh Khairul dkk [3], Hasil pengujian fungsional sistem, web yang dirancang berhasil dengan prosentase $100 \%$. Hasil pengujian Software Webserver Stress Tool, aplikasi yang digunakan melayani hingga 500 user (simulasi) dengan prosentase error $1.73 \%$. Layanan zenziva.id mengirimkan SMS Gateway sebanyak 85 buah Rata-rata penilaian subjektif adalah sebesar 4.1835, dari nilai tersebut terlihat bahwa aplikasi web yang dibuat dinyatakan sangat baik.

Dalam penggunaannya [5], pemanfaatan internet memberikan kemudahan dalam mengakses informasi secara online setiap saat 


\section{Jurnal Sistem Komputer dan Kecerdasan Buatan}

Vol. IV No.2 Tahun 2021

oleh pihak yang membutuhkan. Aplikasi informasi posyandu adalah sebuah aplikasi berbasis web yang memanfaatkan teknologi internet dalam pengelolaan data dan penyampaian informasi. Sebagai aplikasi berbasis web, aplikasi ini adalah website yang dapat diakses oleh pengguna yang membutuhkan informasi terkait posyandu. Aplikasi informasi posyandu dapat mempermudah penyampaian informasi kegiatan di posyandu yang diakses secara online oleh kader posyandu maupun masyarakat.

Slamet dkk [7], menyampaikan dalam penulisannya bahwa Sistem informasi berbasis web ini berisi informasi umum; informasi perkembangan balita, data posyandu, data jadwal, data balita, data imunisasi, info penimbangan, pengaturan data pengguna dan disiarkan melalui gateway SMS. Hasil tes black box tidak menemukan masalah. Sistem Posyandu ini sudah siap untuk diuji coba kepada masyarakat Desa Wanasari, Brebes.

Berdasarkan pemaparan penelitian terkait di atas, maka penulis membuat sistem informasi KMS dengan menggunakan perancangan UML (Unified Modeling Language), metode Waterfall, untuk mengelola data posyandu dengan penambahan akses orang tua mendapatkan memonitoring pertumbuhan anak, serta dapat melihat perkembangan grafik status gizi balita setiap bulannya.

\section{METODOLOGI}

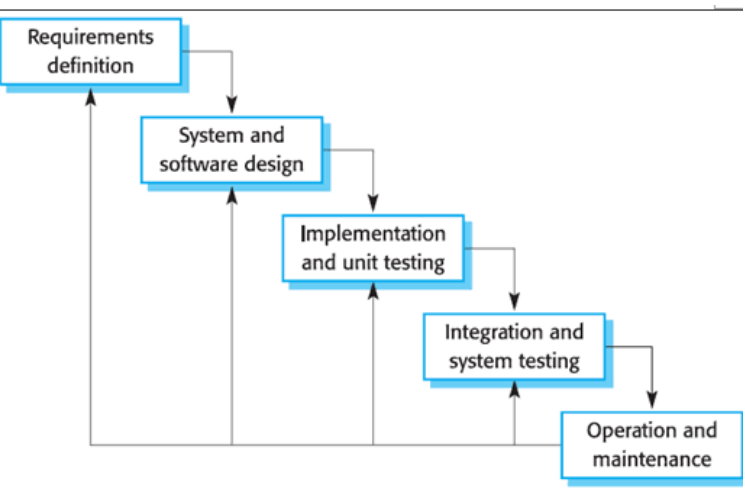

Gambar 1. Ilustrasi Sistem Metode Waterfall

Metode Waterfall merupakan metode yang digunakan dalam penelitian ini. Gambar 1 diatas merupakan tahapan dari metode pengembangan waterfall:

A. Requirments definition :

Dalam langkah ini penulis melakukan sebuah penelitian dengan wawancara, observasi ke
Posyandu dan mengumpulkan data dari study literature.

B. System and Software Design :

Pada tahap ini penulis menggunakan UML (Unified Modeling Language) untuk perancangan sistemnya dan mock up balsamiq untuk user interface.

C. Implementation and unit testing :

Tahapan dalam mengerjakan suatu sistem, setelah selesai selanjutnya dilakukan uji coba pada sistem guna menemukan kesalahankesalahan dan kemudian diperbaiki.

D. Integration and system testing :

Tahapan final sebuah sistem dan digunakan oleh user

E. Operation and maintenance :

Tahapan ini akan mengalami perubahan dan menyesuaikan dengan lingkungan/pelanggan membutuhkan perkembangan fungsional.

\section{HASIL DAN PEMBAHASAN}

Bab ini penulis akan menyampaiakn hasil dari penelitian yang telah dilakukan.

\section{A. Use Case Diagram}

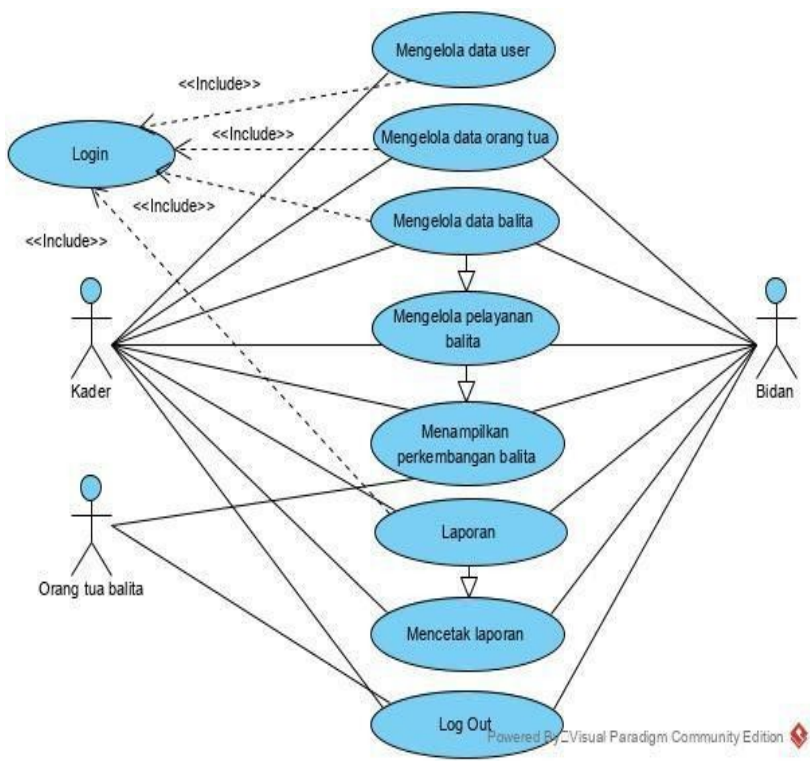

Gambar 2. Use Case Digram KMS Balita

Dalam gambar 2. terdapat 3 (tiga) roles aktor yang digunakan dalam penggunaan Sistem Informasi KMS Balita yaitu Kader, Bidan dan Orang Tua. Kader adalah Aktor yang dapat mengolah semua data dan memiliki hak akses penuh, kader dapat mengelola data user, orang tua, balita, layanan balita kelola berat badan, tinggi badan, melihat laporan, mencetak laporan dan menampilkan perkembangan balita. Bidan adalah Aktor yang dapat mengelola data orang tua, balita, layanan balita kelola imunisasi, 
vitamin dan obat, melihat laporan, mencetak laporan dan menampilkan perkembangan balita. Sedangkan Orang Tua adalah Aktor yang hanya dapat menampilkan perkembangan balita.

\section{B. Class Diagram}

Pada gambar 3. menjelaskan class diagram, dalam pembuatan class diagram penulis telah menentukan object yang dijadikan main class yaitu user, orang tua, balita, pelayanan dan laporan. Masing-masing memiliki attribute dan operation dan relasi yang saling berhubungan.

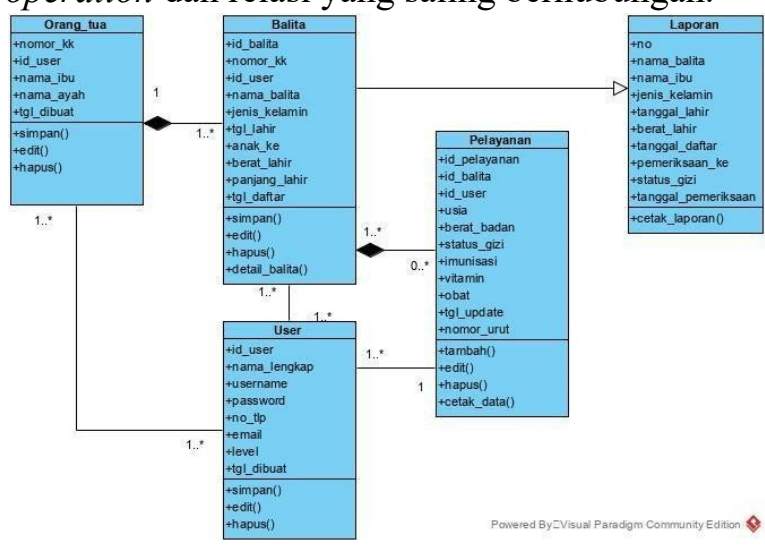

Gambar 3. Class Diagram

\section{Activity Diagram}

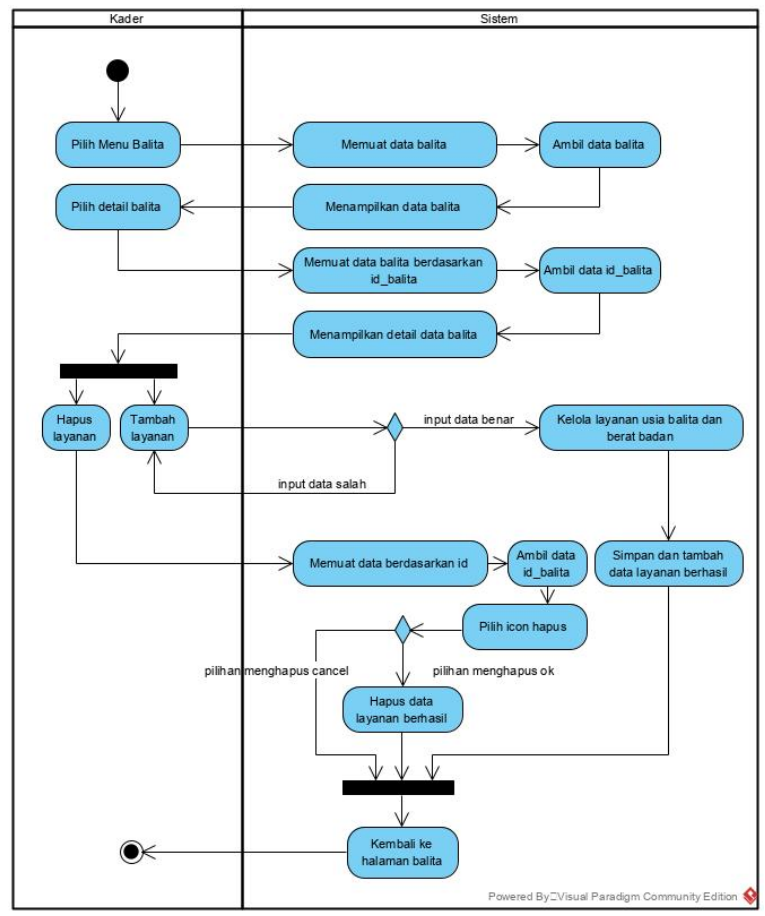

Gambar 4. Activity Diagram Kelola Layanan Kader

Pada kelola layanan kader gambar 4. menunjukkan pengelolaan data kegiatan posyandu dalam pemberian layanan ke balita. Untuk mengakses kelola layanan, kader harus masuk ke menu balita sistem memuat data balita lalu memperoleh data balita dan sistem menampilkan data balita, dari data balita kader memilih detail balita dan sistem memuat data balita berdasarkan id balita lalu mengambil data maka sistem menampilkan detail data balita. Kader bisa menambahkan serta menghapus data layanan, kader hanya dapat mengisi usia balita dan berat badan saja sedangkan imunisasi, vitamin dan obat diisi oleh bidan. Pengolahan terdapat dalam satu activity yang terdapat di menu balita lalu kelola layanan.

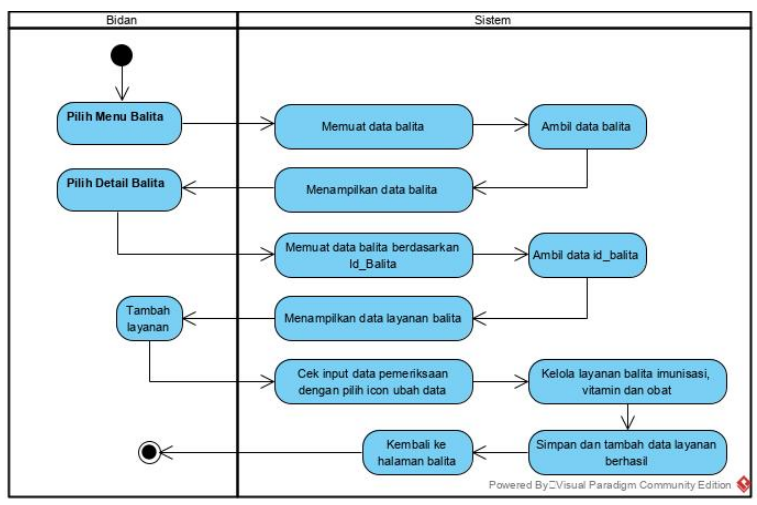

Gambar 5. Activity Diagram Kelola Layanan Bidan

Gambar 5. pada kelola layanan bidan proses yang dijalankan untuk mengakses sistemnya sama dengan kelola layanan kader, perbedaannya bidan mengisi form layanan balita dengan menekan icon edit dari pemeriksaan yang sudah diisi oleh kader. Bidan hanya dapat mengelola data imunisasi, vitamin dan obat.

\section{Sequence Diagram}

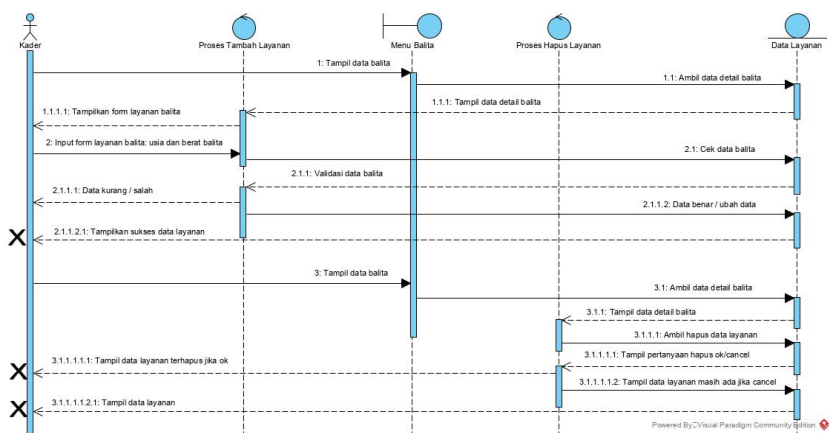

Gambar 6. Sequence Diagram Kelola Layanan Kader

Sequence diagram pada gambar 6 . menjelaskan bagaimana mengelola layanan untuk kegiatan posyandu yang dilakukan oleh kader. Untuk mengakses kelola layanan harus masuk ke menu balita, lalu kader mengambil data detail balita sistem akan menampilkan form layanan balita. Kader dapat menginput form layanan balita dengan mengisi usia dan berat badan balita 


\section{Jurnal Sistem Komputer dan Kecerdasan Buatan \\ Vol. IV No.2 Tahun 2021}

saja, Sistem akan memvalidasi data balita jika data kurang/salah akan kembali ke form data, jika data benar/ubah data maka akan menampilkan sukses data layanan.

Untuk menghapus data layanan kader masuk ke menu balita dan mengambil detail balita, sistem menampilkan data detail balita. Kader dapat mengambil hapus data layanan maka akan tampil pertanyaan hapus ok/cancel, tampil data layanan terhapus jika $o k$ dan tampil data layanan masih ada jika cancel.

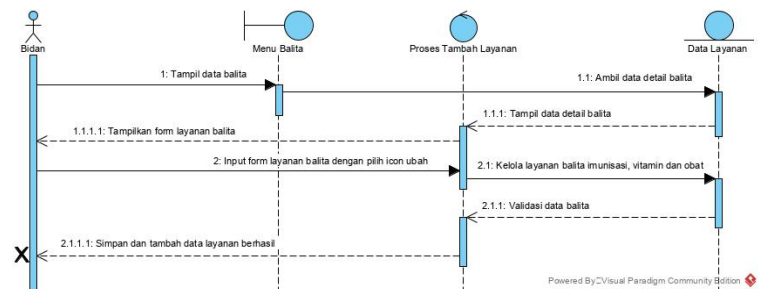

Gambar 7. Sequence Diagram Kelola Layanan Bidan

Sequence diagram pada gambar 7 . menjelaskan bagaimana mengelola layanan untuk kegiatan posyandu yang dilakukan oleh bidan. Untuk mengakses kelola layanan harus masuk ke menu balita, lalu bidan mengambil data detail balita sistem akan menampilkan form layanan balita. Bidan dapat menginput form layanan balita dengan menekan icon ubah pada pemeriksaan balita yang sudah diisi kader dan mengisi data imunisasi, vitamin dan obat. Sistem akan memvalidasi data balita jika sudah selesai maka akan menampilkan sukses data layanan.

\section{E. Implementasi}

1. Halaman Utama

Pada halaman ini ditampilkan halaman utama untuk user masuk/login ke sistem. Tampilan ini merupakan tampilan awal pada website ini, tampilan halaman sama semua untuk user kader, bidan dan orang tua. Halaman utama dapat dilihat pada gambar 8 dibawah ini.

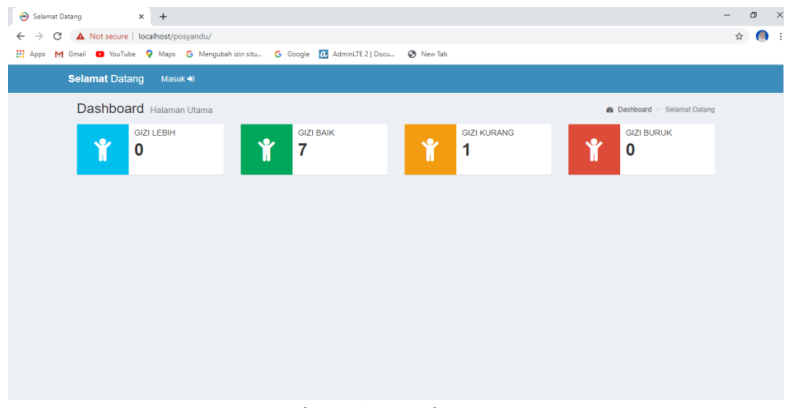

Gambar 8. Halaman Utama
2. Menu $\log$ In

Dalam menu login yaitu dengan menggunakan username dan password saja, hanya user yang sudah diberikan hak akses oleh kader yang dapat mengakses sistem informasi ini. Data user yang sudah ditambahkan oleh kader, user tersebut yaitu kader, bidan dan orang tua balita. Kebutuhan yang diberikan disesuaikan dengan pengguna user, sedangkan kader mempunyai semua hak akses yang ada disistem. Gambar 9 menunjukkan menu login untuk masuk ke sistem terlihat sebagai berikut.

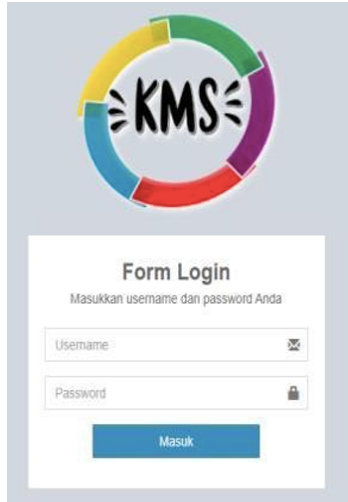

Gambar 9. Menu Log In

3. Menu Data Orang Tua

Pada tampilan menu Orang Tua dapat diakses oleh kader dan bidan, untuk pelaksanaan kegiatannya kader dapat menambah, mengubah, dan menghapus pada data orang tua. Tambah data orang tua dengan mengisi form data yang sudah tersedia pada gambar 10 .

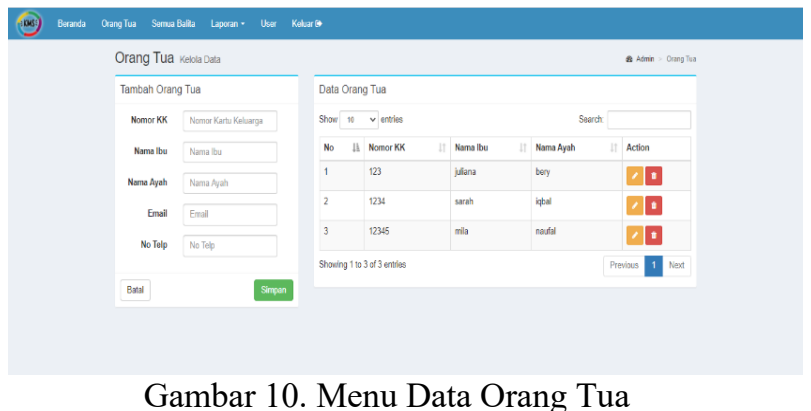

4. Menu Data Balita

Pada tampilan menu balita dapat diakses oleh kader dan bidan, untuk pelaksanaan kegiatannya kader dapat menambah, mengubah, dan menghapus pada data balita. Tambah data balita diisi dari No KK sampai dengan panjang lahir balita harus lengkap lalu disimpan, jika salah satu ada yang kosong maka sistem terbaca data 
salah/kosong. Tambah data balita bisa dilihat pada gambar 8 .

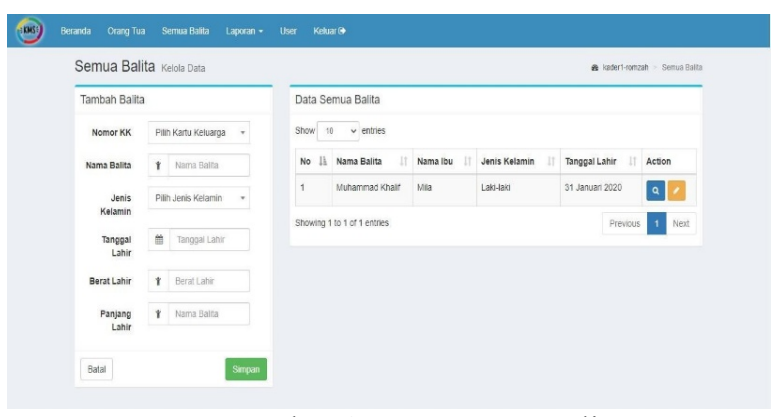

Gambar 8. Menu Data Balita

Pada tampilan menu balita dapat diakses oleh kader, bidan dan orang tua. untuk pelaksanaan kegiatannya kader dapat menambah dan menghapus pada data balita, kader hanya dapat mengisi usia balita dan berat badan balita. Sedangkan bidan dapat mengubah pelayanan balita dengan memasukkan data imunisasi, vitamin dan obat yang diberikan pada balita. Orang tua hanya dapat melihat tampilan grafik perkembangan balita termasuk status gizi balita (sesuai dengan tabel 1) dan pemeriksaan yang sudah diberikan oleh kader dan bidan. Tampilan tambah pelayanan balita terlihat pada gambar 9 .

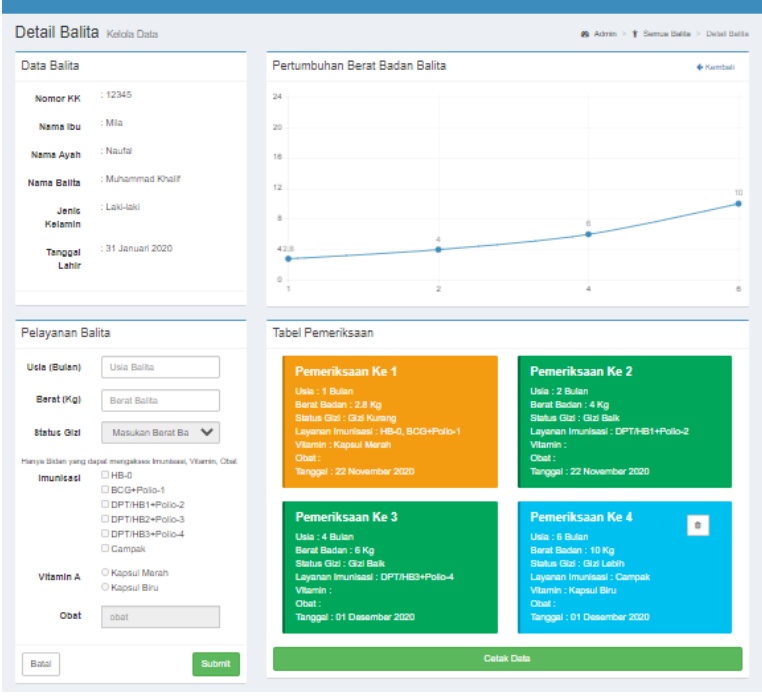

Gambar 9. Pelayanan Balita

5. Laporan

Gambar 10 dibawah ini merupakan laporan data kunjungan balita yang mengikuti kegiatan posyandu, data tersebut di input sesuai balita yang berkunjung. Laporan yang diinginkan dapat diperoleh sesuai tanggal pelaksanaan posyandu.

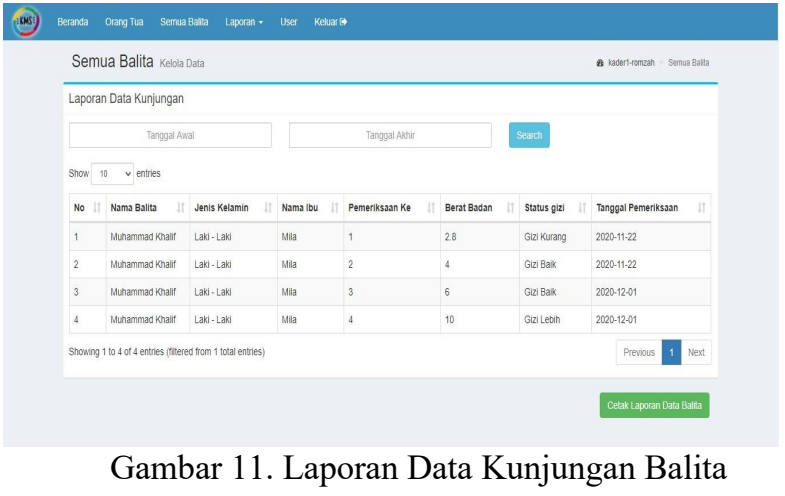

Gambar 12 merupakan laporan data semua balita yang sudah terdaftar di posyandu. Laporan ini hanya dapat diakses oleh kader dan bidan.

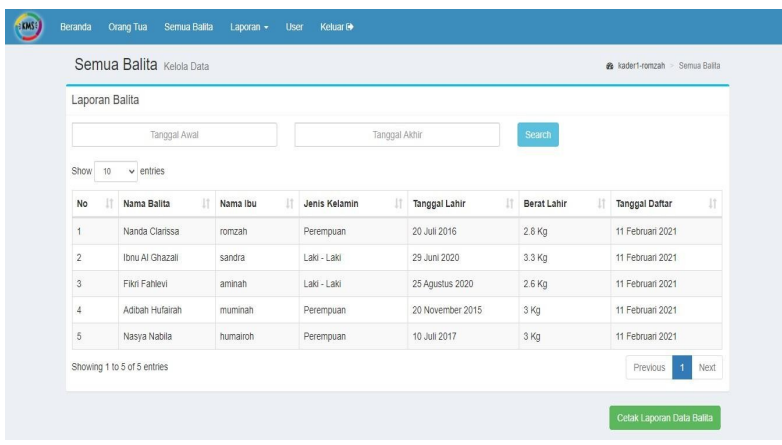

Gambar 12. Laporan Semua Data Balita

\section{Menu Data User}

Pada menu user yang dapat mengakses ke sistem adalah kader saja, kader dapat menambah, mengubah dan menghapus data user. Jika ingin menambah user dapat mengisi form yang sudah tersedia disebelah kiri tampilan menu user, data harus lengkap lalu disimpan. Level menu user ini hanya kader dan bidan sedangkan orang tua langsung tersimpan otomatis di data user ketika data orang tua sudah terdaftar. Berikut tampilan data user disajikan pada gambar 12 yang menunjukkan menu tambah user.

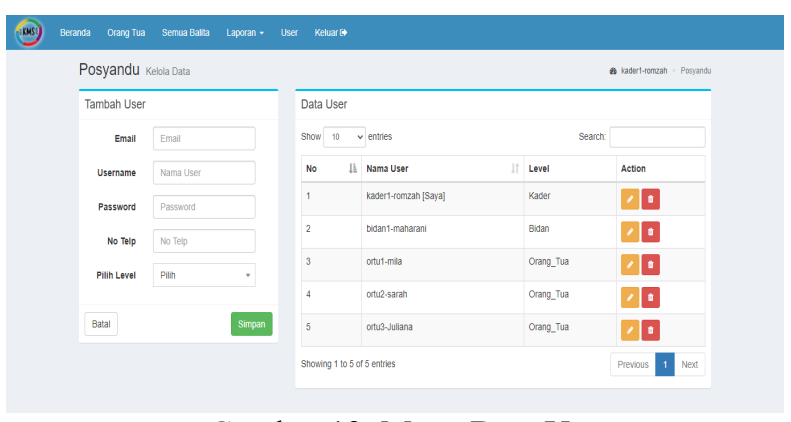

Gambar 13. Menu Data User 


\section{F. Evaluasi Perangkat Lunak}

Pengujian sistem dilakukan dengan pendekatan blackbox testing, metode ini dilakukan tanpa melihat source code program dan dijalankan oleh tester atau user untuk melihat apakah program sudah sesuai dan telah menerima input, lalu proses data, serta menghasilkan output yang sesuai dan berjalan dengan benar.

Hasil uji berdasarkan fungsional aplikasi dapat dilihat pada tabel 2. dibawah ini :

\begin{tabular}{|c|l|l|l|c|c|}
\multicolumn{7}{|c|}{ Tabel 2. Hasil Pengujian Sistem } \\
\hline No & \multicolumn{1}{|c|}{ Test Case } & \multicolumn{1}{|c|}{ Skenario Uji } & \multicolumn{1}{|c|}{$\begin{array}{l}\text { Hasil yang } \\
\text { diharapkan }\end{array}$} & $\begin{array}{c}\text { Hasil } \\
\text { Uji }\end{array}$ & Kesimpulan \\
\hline 1 & $\begin{array}{l}\text { Menambahkan } \\
\text { layanan balita } \\
\text { oleh kader }\end{array}$ & $\begin{array}{l}\text { Mengisi dan } \\
\text { menyimpan } \\
\text { layanan yaitu usia } \\
\text { balita dan berat } \\
\text { badan balita }\end{array}$ & $\begin{array}{l}\text { Data baru layanan } \\
\text { balita tersimpan }\end{array}$ & $\sqrt{ }$ & Valid \\
\hline 2 & $\begin{array}{l}\text { Menambahkan } \\
\text { layanan balita } \\
\text { oleh bidan }\end{array}$ & $\begin{array}{l}\text { Mengisi dan } \\
\text { menyimpan } \\
\text { layanan yaitu } \\
\text { imunisasi, vitamin } \\
\text { dan obat }\end{array}$ & $\begin{array}{l}\text { Data baru layanan } \\
\text { balita tersimpan }\end{array}$ & $\sqrt{ }$ & Valid \\
\hline
\end{tabular}

\section{KESIMPULAN}

Dari pembahasan sebelumnya, dapat disimpukan sebagai berikut:

1. Sistem informasi kartu menuju sehat (KMS) balita memudahkan kader dan bidan melakukan kegiatan di Posyandu dalam hal pendataan ibu dan anak, pelayanan balita seperti penimbangan berat badan.

2. Sistem telah mampu membuat laporan data balita, laporan kunjungan balita dan laporan grafik pertumbuhan balita.

3. Sistem juga memudahkan kader untuk menentukan status gizi balita berdasarkan tabel antropometri penentuan standar gizi.

Future works dalam pengembangan sistem selanjutnya antara lain:

1. Aspek keamanan sistem juga merupakan hal yang penting agar tetap menjaga intervensi dari pihak lain yang mungkin mengganggu sistem ini.

2. Diharapkan ruang lingkup pembahasan tidak hanya tentang pemantauan perkembangan balita saja, melainkan pendataan ibu hamil, ibu menysusui serta kegiatan lainnya.

3. Diharapkan agar kedepannya Sistem Informasi Kartu Menuju Sehat (KMS) Balita Berbasis Web tidak hanya dalam Web Base namun juga dapat dalam bentuk Mobile Base.

4. Diharapkan agar kedepannya Sistem Informasi Kartu Menuju Sehat (KMS) Balita Berbasis Web dapat dikembangkan menjadi sistem yang lebih menarik lagi.

\section{DAFTAR PUSTAKA}

[1] K. K. RI, 2012. Buku saku posyandu. s.1.:s.n.

[2] Mulyani, Widiana, Bambang Eka Purnama. 2015. Pembangunan Sistem Informasi Data Balita Pada Posyandu Desa Ploso Kec. Punung Kab. Pacitan. Journal Speed Sentra Penelitian Engineering dan Edukasi Vol.7 No.2 2015.

[3] Hakim, Muhammad Khairul, Yuyun Siti Rohmah dan Yuli Sun Hariyani. 2017. Sistem Infomasi Kegiatan Posyandu Berbasis Web dan SMS Gateway (Studi Kasus: Perumahan Pesona Bali). eProceedings of Applied Science Vol.3 No.3 2017

[4] Sholihah, Nabila. Sri Kusumadewi. 2015. Sistem Informasi Kesehatan Ibu dan Anak. Prosiding SNATIF Ke-2 Tahun 2015 ISBN: 978-602-1180-21-1

[5] Soleh M, Imam, Ragil Wijianto. 2017. Pengembangan Aplikasi Posyandu Berbasis Web. Jurnal Evolusi Vol.5 No.2 2017

[6] Thamaria, Netty. 2017. Penilaian Status Gizi. Kementrian Kesehatan RI: Pusat Pendidikan Sumber Daya Manusia Kesehatan.

[7] Wiyono, Slamet, Dega Surono Wibowo, and M. Yusuf Bachtiar. 2019. Development of POSYANDU (Pos Pelayanan Terpadu) Information System". Journal Publication \& Information Engineering Research Vol. 3 No. 2 2019. E-ISSN: 2541-2019 P-ISSN: 2541-044x 